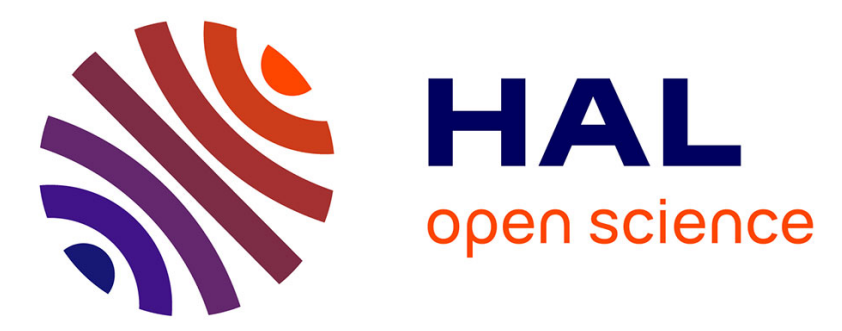

\title{
Strong intrusions of the Northern Mediterranean Current on the eastern Gulf of Lion: insights from in-situ observations and high resolution numerical modelling
}

Nicolas Barrier, Anne Petrenko, Yann Ourmieres

\section{To cite this version:}

Nicolas Barrier, Anne Petrenko, Yann Ourmieres. Strong intrusions of the Northern Mediterranean Current on the eastern Gulf of Lion: insights from in-situ observations and high resolution numerical modelling. Ocean Dynamics, 2016, 66 (3), pp.313-327. 10.1007/s10236-016-0921-7 . hal-01436127

\section{HAL Id: hal-01436127 \\ https://hal-amu.archives-ouvertes.fr/hal-01436127}

Submitted on 16 Jan 2017

HAL is a multi-disciplinary open access archive for the deposit and dissemination of scientific research documents, whether they are published or not. The documents may come from teaching and research institutions in France or abroad, or from public or private research centers.
L'archive ouverte pluridisciplinaire HAL, est destinée au dépôt et à la diffusion de documents scientifiques de niveau recherche, publiés ou non, émanant des établissements d'enseignement et de recherche français ou étrangers, des laboratoires publics ou privés. 
Ocean Dynamics manuscript No.

(will be inserted by the editor)

Strong intrusions of the Northern Mediterranean

Current on the eastern Gulf of Lion: insights from

in-situ observations and high resolution numerical

modelling

Nicolas Barrier • Anne A. Petrenko •

Yann Ourmières

Received: date / Accepted: date

Nicolas Barrier

Aix-Marseille Université, Université de Toulon, CNRS/INSU, IRD, MIO, UM 110, 13288

Marseille, France

Tel.: +33486090612

E-mail: nicolas.barrier@univ-amu.fr

Anne A. Petrenko

Aix-Marseille Université, Université de Toulon, CNRS/INSU, IRD, MIO, UM 110, 13288

Marseille, France

Yann Ourmières

Université de Toulon, CNRS/INSU, IRD, MIO, UM 110, 83957 La Garde, Aix-Marseille

Université, CNRS/INSU, IRD, MIO, UM 110, 13288 Marseille, 
Abstract The Northern Mediterranean Current is the return branch of the cyclonic circulation of the northwestern Mediterranean Sea. Because of geostrophic constraints, this warm and oligotrophic current is forced to flow westward along the continental slope of the Gulf of Lion. But, occasionally, it can penetrate on the shelf and strongly impacts the local biogeochemistry and in turn the primary production. By combining in-situ observations and high-resolution modelling, it is shown that intrusions on the eastern part of the gulf are mainly forced by easterly or northwesterly wind events, through physical mechanisms that are very different in nature.

Easterlies induce a piling of water along the Gulf of Lion coast that drives, through geostrophy, an alongshore shelf-intruding current. This intrusive current occurs independently of the stratification and is concomitant with the wind forcing. On the other hand, intrusions due to northwesterlies only occur during stratified conditions and are related to the development of upwellings along the Var coast. When the upwelling develops, a northwestward alongshore pressure force balances the Coriolis force associated with the onshore flow at depth. When the winds drop, the upwelling relaxes and the onshore flow weakens. Consequently, the Coriolis force no longer counterbalances the pressure force that ultimately dominates the momentum balance, causing the displacement of the Northern Current on the Gulf of Lion shelf approximately one day after the wind relaxation. This time lag between the northwesterlies's decrease and the intrusions permits to anticipate possible changes in the biogeochemistry of the Gulf of Lion. 
Keywords Northern Current · Gulf of Lion · Intrusions · Julio · Upwelling ·

Cross-shelf exchanges · Wind-setup · Easterlies · Mistral · Tramontane •

Northwesterlies

\section{$1 \quad 1$ Introduction}

Coastal areas are a key environment for the marine ecosystem, since they re-

ceive large amounts of nutrients through river outflows that in turn favour

4 phytoplankton activity (Cruzado and Velasquez, 1990). They also play a sig-

5 nificant role in the global biogeochemical cycles of carbon, nitrogen and phos-

6 phorus (Mantoura et al, 1991; Liu et al, 2000). But coastal areas are also

7 subjected to high demographic pressure and consequently to great risks of

8 pollution. In this context, a better understanding of the coastal circulation is

9 critical since it controls the dispersion of anthropogenic and river-discharged

10 pollutants (Huthnance, 1995), but also the advection of nutrients and larvae

11 (Largier, 2003). This is especially true for the Gulf of Lion, which is a wide

12 and shallow continental shelf in the northwestern Mediterranean Sea (Fig. 1),

13 featuring a heavily urbanised shoreline.

14 Several forcings influence the coastal circulation in the Gulf of Lion. The

15 Mistral and the Tramontane (hereafter referred to as northwesterlies) are cold

16 and dry continental gustly winds that occur anytime in the year. They are

17 highly constrained by the orography (Rhône river valley for the Mistral, Pyre-

18 nees and Massif Central for the Tramontane) and may therefore be associated

19 with strong wind curls when they reach the gulf. In winter, through cooling 


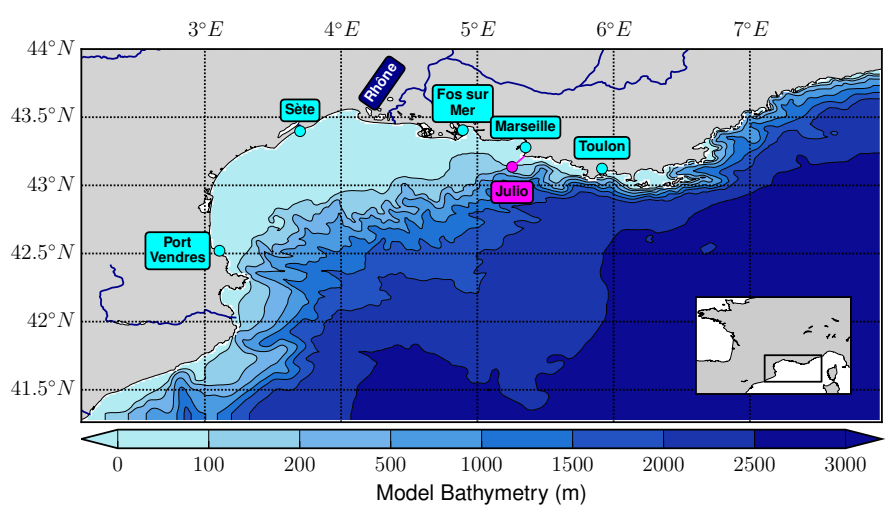

Fig. 1 Bathymetry of the Glazur64 configuration. The locations of the Julio mooring and section are indicated by a magenta point and a magenta line, respectively.

1 and evaporation, they may trigger dense water formation and cascading on the 2 continental shelf (Ulses et al, 2008). While, in summer, they are associated with the development of upwellings (Millot, 1979). East-southeast winds (hereafter referred to as easterlies) carry clouds and rain over the Gulf of Lion and are associated with downwellings. They are less frequent than northwesterlies and are especially strong from autumn to spring (Millot, 1990). In addition to wind 7 forcing, the Gulf of Lion is subjected to the freshwater inputs of the Rhône

8 River. Its plume can extend over large areas when a strong volume discharge 9 is combined with a shallow thermocline (Fraysse et al, 2014). The associated 10 changes in the density field can impact the shelf circulation (Estournel et al, 11 2001; Reffray et al, 2004; André et al, 2005).

The coastal circulation in the Gulf of Lion is also strongly influenced by the 13 large-scale ocean circulation of the Mediterranean. The Northern Current, also 14 known as the "Liguro-Provencal Current", is the northern branch of the cy15 clonic gyre circulation of the northwestern Mediterranean Sea (Millot, 1999). It 
1 originates before the Ligurian Sea from the merging of the Western and East-

2 ern Corsican Currents (Astraldi et al, 1990). This baroclinic current is, at first

3 order, in geostrophic balance and flows westward along the continental shelf.

4 During winter and certain upwelling conditions, the Northern Current sepa-

5 rates the fresh and nutrient-rich coastal waters from the salty and oligotrophic

6 offshore waters. But, as evidenced in observations and numerical modelling,

7 the Northern Current occasionally penetrates over the Gulf of Lion, causing

8 drastic changes in the biogeochemistry and in turn in the primary production

on the shelf (Ross et al, in revision.).

Intrusions of a slope current on an adjacent shelf have already been ev-

11 idenced elsewhere in the world ocean, such as the surface intrusions of the

12 Gulf Stream (Oey et al, 1987; Gawarkiewicz et al, 1992) and of the Kuroshio

13 (Chen et al, 1996; Tang et al, 1999; Wu et al, 2005; Caruso et al, 2006).

${ }_{14}$ Oey et al (1987) and Chen et al (1996) suggest that these intrusions are likely

15 forced by wind-induced onshore Ekman transport. Wu et al (2005) and Caruso

16 et al (2006) suggest that they are forced by strong wind-stress curls. Other

17 causes are also proposed, such as the meanderings of the main current (Oey

18 et al, 1987) or the abrupt changes in bottom topography (Chen et al, 1996).

19 The Gulf-Stream and the Kurushio currents are poleward currents that are

20 strongly influenced by the $\beta$-effect, contrary to the Northern Current that is

${ }_{21}$ more zonally oriented. Other intrusions, more similar to those occurring on

22 the Gulf of Lion, have been evidenced on the northwestern shelf of the Black

${ }_{23}$ Sea (Oguz and Besiktepe, 1999; Korotaev et al, 2003) or on the Papua Gulf 
1 in New Guinea (Wolanski et al, 1995). However, the physical mechanisms of

2 these intrusions have not been investigated yet.

Intrusions of the Northern Current on the eastern part of the Gulf of Lion

4 have been investigated by Gatti et al (2006) and Gatti (2008), using a combi-

5 nation of in-situ observations and numerical modelling. The authors suggest

6 that some intrusions are forced by easterlies, through either Ekman transport

7 or a shoreward displacement of the Northern Current. They also propose that

8 northwesterlies may favour intrusions through the associated positive wind-

9 stress curl. This curl would provide a source of vorticity to the Northern

10 Current that may drive intrusions. She also suggests that intrusions on the

11 eastern part of the Gulf of Lion are also likely to occur after the relaxation

12 of upwelling-favourable winds, as shown by Millot and Wald (1980). Using

13 analytical model and numerical simulations, Echevin et al (2003) assessed the

14 interaction between a coastal current, represented as a baroclinic Kelvin wave,

15 and a shelf break. They suggest that Ekman transport associated with south-

16 easterlies induce a downwelling, which in turn generates a westward coastal

17 current that transports Northern Current waters onto the shelf.

Therefore, although the intrusions of the Northern Current on the eastern 19 part of the Gulf of Lion have been shown to be wind-driven, the associated ${ }_{20}$ physical mechanisms remain unclear. Furthermore, the potential influence of ${ }_{21}$ the ocean stratification is also not well understood. For instance, Millot and 22 Wald (1980) suggest that intrusions of the Northern Current occur when the 
1 ocean is stratified, while Petrenko (2003) has shown that intrusions may be

2 observed independently of stratification.

The aim of the present study is to address these uncertainties and therefore

4 to gain more understanding on the physical mechanisms behind the intrusions

5 of slope current on continental shelves. Using a combination of ADCP current

6 observations, tide-gauge data and regional high resolution numerical mod-

7 elling, the physical mechanisms that link the wind forcings and the intrusions

8 on the eastern part of the gulf are investigated for the 2012-2013 period. The

9 paper is organised as follows. In section 2, the observations and numerical

${ }_{10}$ model are described. In section 3 , the methodology used in the detection of

11 simulated and observed intrusions is presented. Section 4 is dedicated to the

12 analysis of the physical mechanisms that drive the intrusions. Conclusions and

${ }_{13}$ discussions are provided in section 5.

\section{Data description}

$15 \quad 2.1$ Julio mooring

16 Gatti (2008) has suggested that the Julio ${ }^{1}$ site, located on the $100 \mathrm{~m}$ isobath

17 at $5.255^{\circ} \mathrm{E}-43.135^{\circ} \mathrm{N}$ (magenta point in Fig. 1), is a judicious location for the ${ }_{18}$ observation of intrusions occurring on the eastern side of the Gulf of Lion. As 19 such, it has been proposed as a site in the framework of the MOOSE ${ }^{2}$ observing system (http://www.moose-network.fr/). A bottom-moored ADCP (RDI

\footnotetext{
1 Judicious Location for Intrusion Observation

2 Mediterranean Ocean Observing System for the Environment
} 
1 Ocean Sentinel, $300 \mathrm{kHz}$ ) at the Julio site is exploited from 2012-02-12 to

2 2012-10-23 and from 2013-09-26 to 2013-12-31. It provides measurements of

3 the horizontal currents every 30 minutes and every $4 \mathrm{~m}$ depth between $15 \mathrm{~m}$

4 and $92 \mathrm{~m}$.

$5 \quad 2.2$ Sonel tide-gauge data

6 Daily tide-gauge observations at Fos sur Mer, Sète and Port Vendres (see 7 locations on Fig. 1) are downloaded from the Sonel website (Sonel stands 8 for "Système d'Observation du Niveau des Eaux Littorales"; website: http:

9 //www.sonel.org/). The inverted barometer effect $\eta^{i b c}$ is computed following 10 Ponte (2006) by:

$$
\eta^{i b c}=-\frac{p_{a}-\overline{p_{a}}}{\rho_{0} g}
$$

11 and is subtracted from the raw daily timeseries. $p_{a}$ is the atmospheric sea12 level pressure and $\overline{p_{a}}$ its long-term mean (computed on the 1979-2014 period), ${ }_{13} \rho_{0}$ the reference density of water (here, $1000 \mathrm{~kg} \cdot \mathrm{m}^{-3}$ ) and $\mathrm{g}$ the gravity. The 14 sea-level pressure used here is issued from the ERA-Interim reanalysis of the 15 European Centre for Medium-Range Weather Forecasts (Dee et al, 2011).

16 2.3 High-resolution numerical modelling

${ }_{17}$ The physical mechanisms that drive the intrusions of the Northern Current on 18 the eastern part of the Gulf of Lion are investigated using the high resolution 19 model simulations of Guihou et al (2013), which are derived from the Glazur64 
1 configuration of Ourmières et al (2011). Glazur64 is based on the "Nucleus for

2 European Modelling of the Ocean" modelling framework (NEMO, Madec, 3 2008) and is implemented on a $1 / 64^{\circ}$ regular grid with 130 vertical z-levels,

4 spacing from $1 \mathrm{~m}$ near the surface to $30 \mathrm{~m}$ near the bottom. The ocean bound-

5 ary conditions at the eastern and southern parts of the domain use radiative

6 type conditions (Cailleau et al, 2008), with boundary data prepared from the

7 basin-scale PSY2V4R1 operational configuration provided by MERCATOR-

\& OCEAN (http://www .mercator-ocean.fr). The damping coefficients for the

9 inflows and the outflows are 1 and 10 days, respectively.

10 Surface boundary conditions are provided by the Météo France operational 11 regional model Aladin. This atmospheric model features data assimilation and 12 state-of-the-art atmospheric physics (Fischer et al, 2005). It has a horizontal ${ }_{13}$ resolution of around $1 / 10^{\circ}(9.5 \mathrm{~km})$ and forcings are provided every $3 \mathrm{~h}$. Such 14 spatio-temporal resolution has shown to well reproduce specific wind systems, 15 diurnal cycles and sea breeze, hence leading to a valuable improvement of the 16 mesoscale circulation simulated by the ocean model (Schaeffer et al, 2011).

${ }_{17}$ The reader interested in the details of the Glazur64 configuration are referred 18 to Guihou et al (2013).

2.4 Comparison of Glazur64 with the Julio mooring

${ }_{20}$ The time-averaged simulated velocity profiles at the Julio site are compared ${ }_{21}$ with the observed ones. The meridional component is fairly well captured by 22 the model simulation, both in term of magnitude and vertical structure (Fig. 2, 

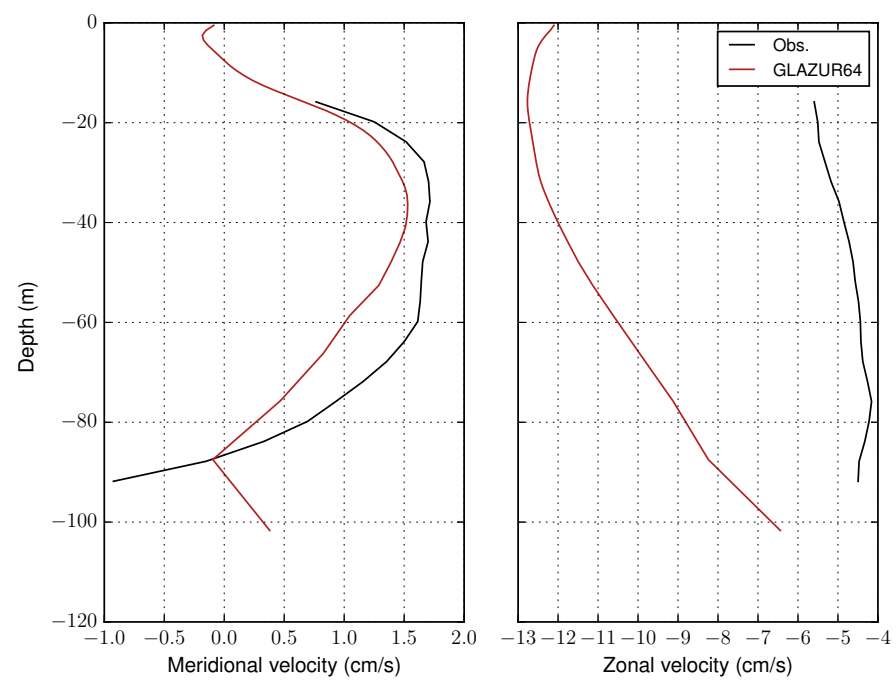

Fig. 2 Time-averaged of the observed (black) and simulated (red) velocity profiles at the Julio site, computed over the overlapping time period between the observations and model simulation (from February to the end of October 2012, and from October to December 2013).

1 left panel). However, Glazur64 strongly overestimates the zonal component of 2 the current at the Julio site (Fig. 2, right panel): the simulated zonal velocity 3 is indeed twice as large as the observed one and shows a large weakening 4 at depths, while the observed profile is more homogeneous. This discrepancy 5 is presumably due to a misposition of the simulated Northern Current, which 6 may be too close to the coast hence encroaching on the Julio location. However,

7 this model bias is not critical for the comparison of observed and simulated 8 intrusions. Indeed, more relevant indexes to detect the presence of intrusions 9 will be presented in the following section 


\section{Detection of Northern Current's intrusions}

2 The intrusions of the Northern Current on the eastern part of the Gulf of Lion

3 have been detected using the Julio ADCP mooring observations as follows.

4 First, the current component that flows perpendicular to the Julio section

5 (magenta line at angle $\theta=49.4^{\circ}$ from north in Fig. 1) has been computed

6 using the measured zonal and meridional velocities:

$$
U_{j u l}=V \cos \theta-U \sin \theta
$$

7 with $V$ and $U$ the meridional and zonal velocities at the Julio mooring. By

8 convention, $U_{j u l}$ is counted positive for a northwestward flowing current. Then,

9 $U_{j u l}$ has been vertically averaged, hence leading to a half-hourly time-series,

10 on which daily averaging has been performed. Finally, the resulting daily time-

11 series has been standardised: the temporal mean, computed over the overlap-

12 ping time-period between the observations and model simulation, has been

13 removed and the resulting anomalies have been divided by their standard de-

14 viation. The resulting standardized index, which will be referred to as the

15 "observed" Julio index, is shown in Fig. 3 (black line). In the following, we

16 will consider that intrusions occur, in the in-situ data, when the observed Julio

${ }_{17}$ index is greater than 1, i.e. when the depth-averaged across-section velocity

18 exceeds its mean by 1 standard deviation.

19 The same methodology is applied on the Glazur64 model simulation at

${ }_{20}$ the grid point the closest to Julio. As expected from figure 2, the temporal

${ }^{21}$ mean of the simulated $U_{j u l}$ velocity is overestimated when compared with 


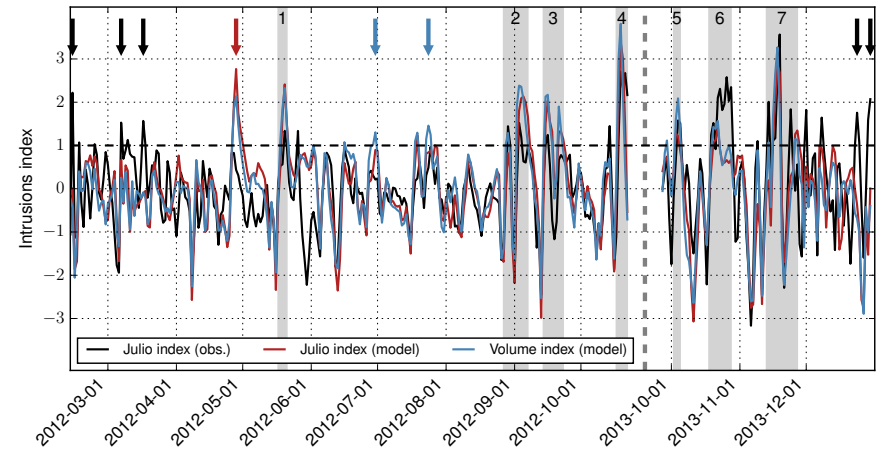

Fig. 3 Observed (black line) and simulated (red and blue lines) standardised intrusion indexes. Only the overlapping time period between the observations and model simulation (from February to the end of October 2012, and from October to December 2013) is shown. Black arrows indicate intrusion events that are observed but not simulated, the red arrow indicates the simulated intrusion event which is not observed and blue arrows highlight simulated intrusions that are captured by the volume index but not by the Julio one. The vertical dotted line separates the two time series. The horizontal dotted line corresponds to the detection threshold. The grey shadings highlight the intrusion events that are investigated in section 4

1 the observed one $\left(8.4 \mathrm{~cm} . \mathrm{s}^{-1}\right.$ and $4.3 \mathrm{~cm} . \mathrm{s}^{-1}$, respectively). However, their 2 standard deviations are very similar $\left(10.3 \mathrm{~cm} . \mathrm{s}^{-1}\right.$ and $9.1 \mathrm{~cm} . \mathrm{s}^{-1}$ for the 3 observations and model simulation, respectively). The simulated standardized

4 Julio index (red line in Fig. 3) shows a correlation of 0.59 with the observed 5 index. This correlation is significant at the $95 \%$ level of confidence, according to 6 a Student t-test in which the number of degrees of freedom has been corrected 7 from the 1-day lag autocorrelation of both time series (Bretherton et al, 1999).

8 As shown in Fig. 3, there is a good agreement between the occurrence of the 9 simulated and observed intrusions, in spite of the overestimated zonal velocity 
1 simulated at Julio. The model simulation can therefore be considered as robust

2 enough to investigate the physical mechanisms that are responsible for the

3 intrusions.

$4 \quad$ Nevertheless, there are some examples when the two indexes are out of 5 phase. For example, five intrusion events are observed but are not reproduced 6 in Glazur64 (black arrows on Fig. 3). On 2012-02-14, the observed index has 7 a value of 2.2 , while the simulated one has a value of 0.0 . On $2012-03-07$ the 8 observed index is 1.5 and the simulated one is 0.7 , while on $2012-03-17$, the ob9 served index is 1.56 and the simulated one is -0.1 . On 2013-12-24, the observed 10 Julio index reaches 1.7 and remains above 1 the next day, while the simulated 11 index has a value of -0.4. On 2013-12-29, the observed Julio index reaches 1.6 12 and increases up to 2.1 the next day, while the simulated Julio index has a 13 value of -1.5. Conversely, one strong intrusion event is simulated on 2012-041427 by the model but is not observed (red arrow on Fig. 3). At this time, the 15 simulated Julio index reaches 2 and remains above 1 the following 4 days, with 16 a maximum value of 2.8 on 2012-04-28. The observed index also shows an in17 crease but remains below the detection threshold. These discrepancies might ${ }_{18}$ be due to an underestimation by the numerical model of the higher levels of 19 instability of the Northern Current during winter, or to a misrepresentation 20 of wind forcings by the Aladin model. However, the lack of data observations ${ }_{21}$ prevents us from providing robust conclusions. Therefore, we decided to con${ }_{22}$ centrate our efforts on the understanding of the forcing mechanisms of the 23 intrusions which are both observed and simulated. 
In order to assess the robustness of the Julio index in the detection of 2 intrusive events, another methodology is added in Glazur64. Daily volume transport across the Julio section is computed by using the "Physical Analy4 sis of the Gridded Ocean" (PAGO) suite of programs (Deshayes et al, 2014) ${ }^{3}$. 5 PAGO permits the computation of transport indexes along predefined sections 6 with limited interpolation by connecting two section endpoints as a continu7 ous sequence of grid faces following a great circle pathway. Current velocities 8 along the section do not undergo any interpolation, hence allowing a better 9 precision on the volume transport calculation. The calculated volume trans10 port is standardised in the same way as the Julio index. This simulated volume 11 index (blue line in Fig. 3) is highly correlated with the simulated Julio index 12 (correlation of 0.92 , significant at the $95 \%$ level of confidence), and both simu13 lated indexes detect the same intrusion events. Therefore, the simulated Julio 14 index provides a good indicator of the simulated volume transport between 15 the coast, and the comparison between the in-situ and simulated Julio indexes 16 provide a good indicator for concomitant intrusion events.

However, we can mention the rare cases of intrusions that are confined very 18 close to the coast. These intrusions are characterized by a simulated volume 19 index that is above 1 and by Julio indexes (observed and simulated) that are less than 1 (blue arrows of Fig. 3). This is for instance the case for the intrusion event that starts on 2012-07-23, during which the simulated volume transport

\footnotetext{
3 See also http://www. whoi.edu/science/Po/pago/
} 
Table 1 List of intrusions that are investigated in section 4. NW stands for northwesterlies and $\mathrm{E}$ for easterlies.

\begin{tabular}{cccc} 
Number & Start Date & End Date & Wind Forcing \\
\hline I1 & $2012-05-18$ & $2012-05-21$ & NW+E \\
I2 & $2012-08-28$ & $2012-09-07$ & NW \\
I3 & $2012-09-15$ & $2012-09-23$ & NW \\
I4 & $2012-10-18$ & $2012-10-22$ & NW+E \\
I5 & $2013-10-03$ & $2013-10-05$ & E \\
I6 & $2013-10-19$ & $2013-10-28$ & E \\
I7 & $2013-11-14$ & $2013-11-27$ & NW + E
\end{tabular}

1 index is above 1 for 3 days, while the simulated Julio index reaches a maximum 2 of 0.9 , hence below the detection threshold.

\section{Physical mechanisms of the intrusions}

4 In this section, the physical mechanisms associated with the intrusions are

5 investigated. We have focused our attention only on strong intrusion events

6 (grey shadings in Fig. 3, see also Table 1), during which all three intrusion

7 indexes are larger than 1 at least one day, hence corresponding to variations

8 superior to their standard deviations. Moreover, we chose to merge intrusions

9 when only 1 or 2 days separate them. It is the case of intrusions I2 and I3

10 that both include two intrusions when one looks at at the details of Fig. 3.

${ }_{11}$ The physical mechanisms associated with these intrusion events are described

12 in the following. 
$1 \quad 4.1$ Intrusions due to easterlies

2 Intrusions I5 and I6 occur during easterly wind conditions. As discussed in

3 the introduction, easterlies carry rain and clouds over the Gulf of Lion. In

4 the model simulation, intrusions due to easterlies are associated with a very

5 strong increase in sea-surface height over the Gulf of Lion, as shown for in-

6 stance in Fig. 4 for intrusion I6. Such an increase is also evidenced in the Sonel

7 tide-gauge observations: sea-surface height at Fos sur Mer and Sète shows an

8 increase of approximately $20 \mathrm{~cm}$ during intrusions 5 and 6 (Fig. 5). This in-

9 crease is in agreement with the wind setup mechanism proposed by Csanady

10 (1982), which characterizes a balance between the wind-stress and the hor-

11 izontal pressure gradients associated with the sea-level slope. The increase

12 in across-shore pressure gradient induces a geostrophic westward alongshore

13 current until $4^{\circ} \mathrm{E}$ and southwestward west of $4^{\circ} \mathrm{E}$.

As discussed in Fraysse et al (2014), easterlies are also associated with 15 downwelling conditions along the coast. In the model simulation, downwelling 16 indeed occurs, as confirmed by the presence at $20 \mathrm{~m}$ depth of diluted freshwater ${ }_{17}(S \approx 37.2)$ originating from the Rhône river (Fig. 6, panel c), consistently with ${ }_{18}$ Fraysse et al (2014). This freshwater plume is then advected westward past $4^{\circ} \mathrm{E}$ 19 by the intruding current (Fig. 6, panels d and e). Furthermore, as discussed 20 by Echevin et al (2003), the downwelling of warm (in summer) and freshwater ${ }_{21}$ may also contribute significantly to the westward coastal current.

22 Fig. 7 shows the smoothed, daily climatology of the simulated temperature ${ }_{23}$ at Julio, which represents well what occurs in the region (data not shown). It is 

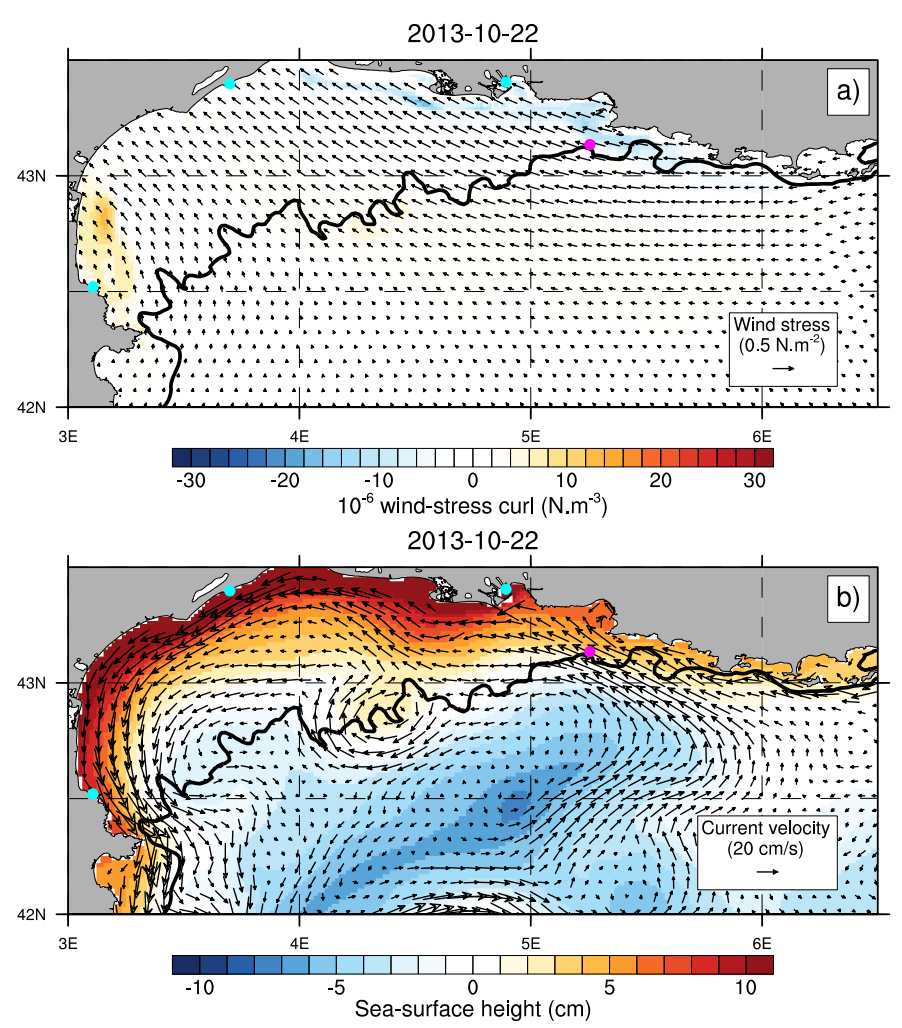

Fig. 4 Top panel: simulated wind-stress (arrows) and wind-stress curl (color shadings) during intrusion I6. Bottom panel: simulated sea-surface height (color shadings) and $20 \mathrm{~m}$ current velocity (arrows) during intrusion I6. The locations of the Sonel tide-gauge stations and of the Julio mooring are shown in cyan and magenta, respectively. The 200-m isobath is shown with a bold black line.

1 constructed as follows. For each water depth, the daily climatology is computed 2 over the 2012-2013 period of the simulation and the FFT coefficients of this 3 climatology are computed. Then, all the harmonics but the annual and semi4 annual ones are artificially set to 0 . The smoothed daily climatology is finally 5 reconstructed by computing the inverse FFT on these new FFT coefficients. As 6 can be inferred from Fig. 7, intrusions I5 and I6 occur in November when the 


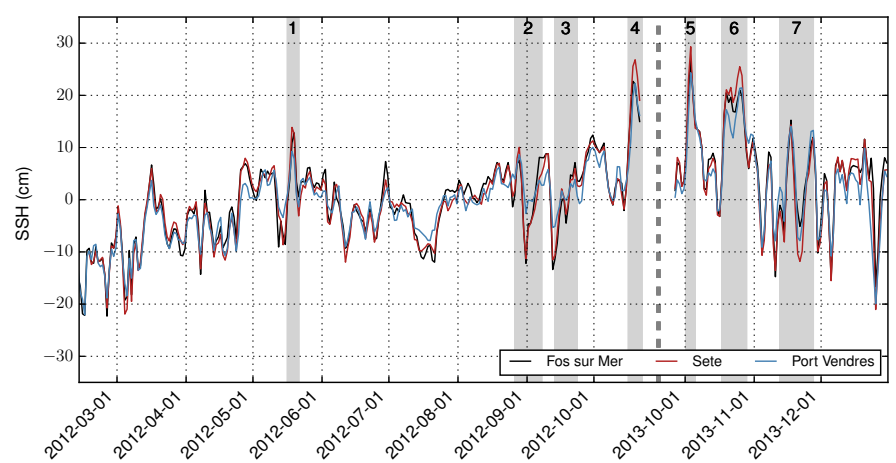

Fig. 5 Daily sea-surface height anomalies from the Sonel dataset corrected from the inverted barometer effect (see section 2.2 for details). Anomalies have been computed by removing the 2012-2013 mean. The vertical dotted line separates the two time series. The grey shadings highlight the intrusion events that are investigated in section 4 .

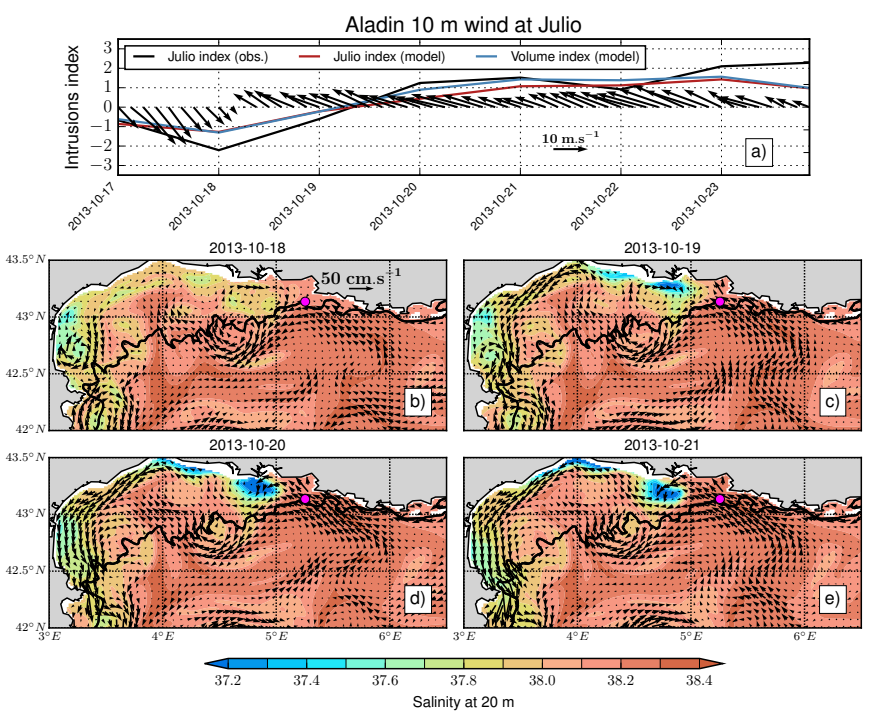

Fig. 6 Top panel: Aladin wind at Julio (arrows) and intrusion indexes (lines). Bottom panels: simulated salinity (color shadings) and ocean currents (arrows) at $20 \mathrm{~m}$ during intrusion I6. The 200-m isobath is shown with a bold black line. 


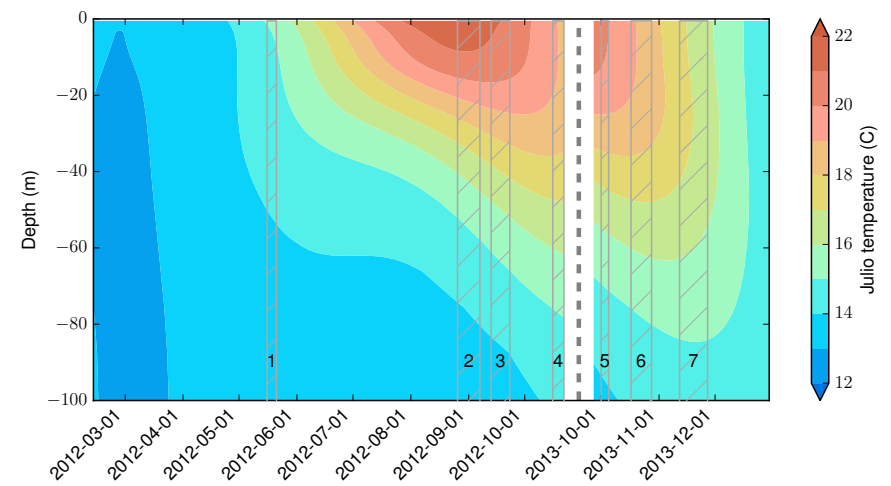

Fig. 7 Hövmoller diagram of the smoothed daily climatology of the simulated temperature at the Julio location (annual and semi-annual harmonics retained, see text for details). The vertical dotted line separates the two time series. The grey hatchings indicate the intrusion events that are investigated in section 4 .

1 ocean is stratified. However, intrusions induced by easterlies may also occur

2 during unstratified conditions, as for instance between 2012-04-27 and 2012-

3 05-01. As shown in Fig. 3, the simulated Julio and volume indexes are greater

4 than 2 , hence suggesting that a very strong intrusion occurs in the model

5 simulation at this time. This April intrusion shows the same characteristics as

6 intrusions I5 and I6. We can then conclude that given the barotropic nature

7 of the mechanism described above, intrusions in response to easterlies occur

8 independently of the stratification.

$9 \quad 4.2$ Intrusions due to northwesterlies

10 Intrusions I2 and I3 are induced by strong northwesterly wind bursts on 2012-

11 08-26 and 2012-08-31 for I2 (top panel of Fig. 8), 2012-09-13 and 2012-09-19

12 for I3. These wind events are followed by intrusions of the Northern Current 
1 that reach the Julio location one day after the wind relaxation, i.e. on 20122 08-28 and 2012-09-02 for I2, on 2012-09-15 and 2012-09-21 for I3. Indeed, 3 one can observe negative indexes during I2 and I3 concomittant with blowing

4 northwesterlies, and positive indexes after their relaxation (top panel of Fig.

$58)$.

Using satellite sea-surface temperature, Millot and Wald (1980) have shown

7 that such wind patterns are favourable to upwellings along the Gulf of Lion 8 coasts and that, when the wind relaxes, the frontal zone between the cold 9 upwelled waters and the warm waters originating from the Northern Current 10 tends to move northwestward and to penetrate over the shelf. As shown in ${ }_{11}$ Fig. 8 for intrusion I2, this behaviour is reproduced by the Glazur64 model 12 simulation. When the wind blows, the ocean currents at $20 \mathrm{~m}$ beyond the 200 ${ }_{13} \mathrm{~m}$ isobath are southwestward, reflecting the ocean response to wind-stress via ${ }_{14}$ Ekman transport (Fig. 8, panel b). Upwellings start developing along all linear 15 coasts and shows maximum vertical velocities on the shelf between Marseille 16 and Toulon, collocated with the strongly positive wind-stress curl (data not 17 shown). The upwelling reaches its maximum amplitude on 2012-09-01 (Fig. 8, 18 panel c), when the wind relaxes. The Northern Current reaches the Julio location on 2012-09-02 (Fig. 8, panel d), hence one day after the wind relaxation. northwesterlies (Fig. 9) is very different from the one associated with the intrusions driven by easterlies (Fig. 4). First, the sea-surface height on the Gulf 23 of Lion coast is not much impacted. This is further confirmed by the observa- 


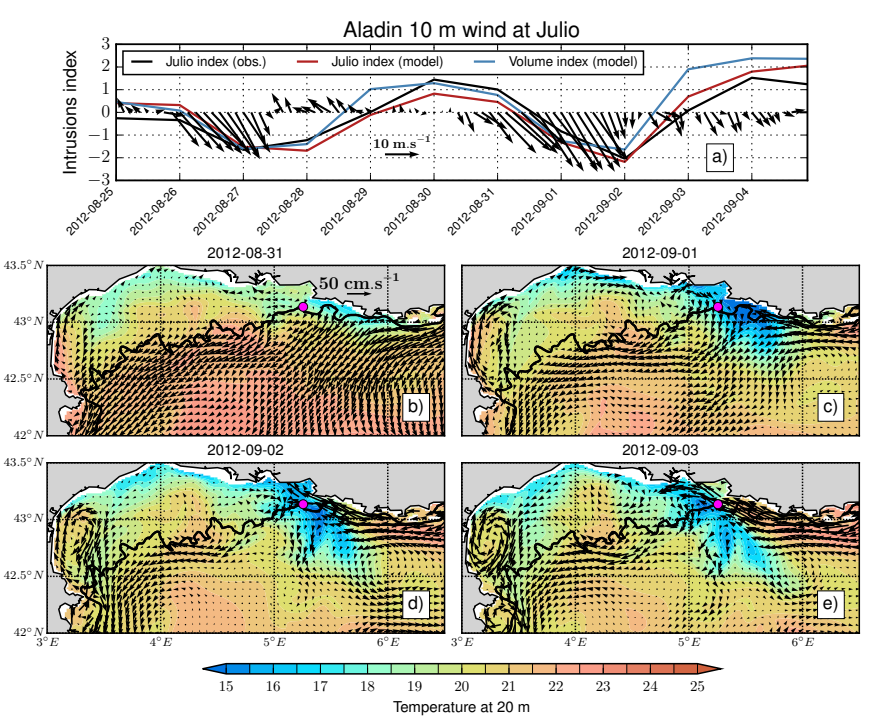

Fig. 8 Top panel: Aladin wind at Julio (arrows) and intrusion indexes (lines). Bottom panels: simulated temperature (color shadings) and ocean currents (black arrows) at $20 \mathrm{~m}$ during intrusion I2. The 200-m isobath is shown with a bold black line.

1 tions at the Sonel stations during intrusions I2 and I3, which show a decrease 2 and negative anomalies rather than the increase and positive anomalies of the 3 other intrusions (Fig. 5). Furthermore, one can observe that the sea-surface 4 height pattern on 2012-09-03 (Fig. 9) shows negative values centred at ap5 proximately $6^{\circ} \mathrm{E}, 42.5^{\circ} \mathrm{N}$, which are tilted northwestward, and positive values 6 on the shelf along the Var coast. The negative values near $6^{\circ} \mathrm{E}$ and $43^{\circ} \mathrm{N}$ are 7 collocated and move with the cold temperature pattern of Fig. 8 (Fig. 8, pan8 els c, d, e). This sea-surface height pattern is associated with positive zonal 9 gradients near $5.25^{\circ} \mathrm{E}$ and with negative zonal gradients near $5^{\circ} \mathrm{E}$. Interest10 ingly, these gradients provide a good indicator of the pressure gradients at $1120 \mathrm{~m}$ (data not shown). The positive pressure gradients on the east induce a 

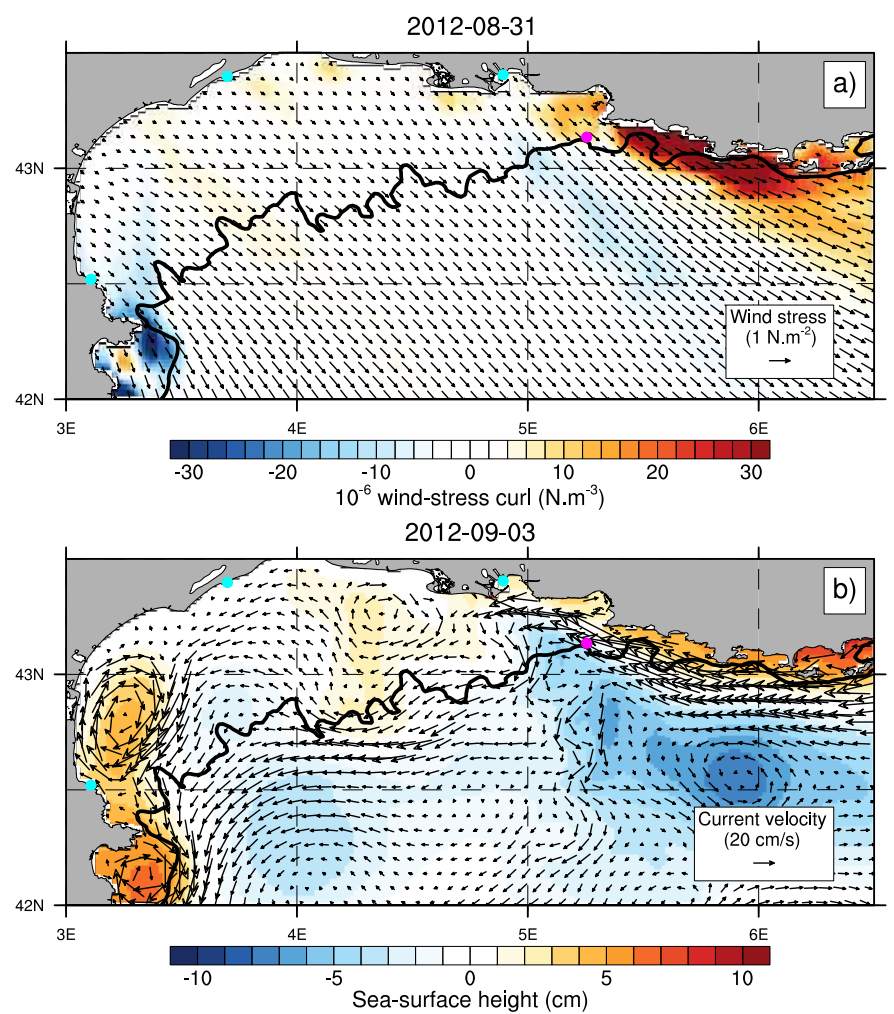

Fig. 9 Top panel: simulated wind-stress (arrows) and wind-stress curl (color shadings) during intrusion I2. Bottom panel: simulated sea-surface height (color shadings) and $20 \mathrm{~m}$ current velocity (arrows) during intrusion I2. The locations of the Sonel tide-gauge stations and of the Julio mooring are shown in cyan and magenta, respectively. The 200-m isobath is shown with a bold black line.

1 northwestward force that is likely to be responsible for the displacement of the

2 Northern Current on the Gulf of Lion shelf.

This evolution of the Northern Current after northwesterly wind bursts can

4 be related to what happens on the continental shelf off California, as described

5 by Gan and Allen (2002). During northwesterly upwelling favourable winds, 6 negative zonal pressure gradients develop west of the Cape Croisette (located 
1 south of Marseille, at the north-eastern end of the Julio section, Fig. 1), bal-

2 ancing the nonlinear advective effects, while east of the cape, positive zonal 3 pressure gradients geostrophically balance the onshore flow at depth. When

4 the northwesterly winds drop, the upwelling relaxes and the Coriolis force no

5 longer counterbalances the westward pressure force that ultimately dominates

6 the momentum balance, hence accelerating the current westward. But west of

7 capes, the eastward pressure force is still balanced by the nonlinear advective

8 effects and hence does not contribute to accelerate the current eastward. The

net effect is therefore a westward flowing current.

11 year, northwesterlies do not always yield intrusions. For example, in 2012-03-

1205 , the simulated wind-stress is very close to the one simulated on 2012-08-31

${ }_{13}$ (compare Fig. 10 with Fig. 9). But this wind burst is not associated with an 14 upwelling nor with an intrusion on the following days (Fig. 10).. The tem15 perature pattern following the wind burst shows colder temperatures on the 16 western Gulf of Lion coasts and rather homogenous temperatures in the open 17 sea (figure not shown). Simulated daily temperature anomalies at Julio, com${ }_{18}$ puted by removing the smoothed seasonal cycle shown in Fig. 7, show reduced variance between December and April both at the surface and at $20 \mathrm{~m}$ depth 20 (data not shown). This tends to confirm the absence of upwellings during the ${ }_{21}$ unstratified winter season. A similar behaviour has been evidenced on the 22 North Carolina shelf by Lentz (2001), who suggests that, during unstratified 


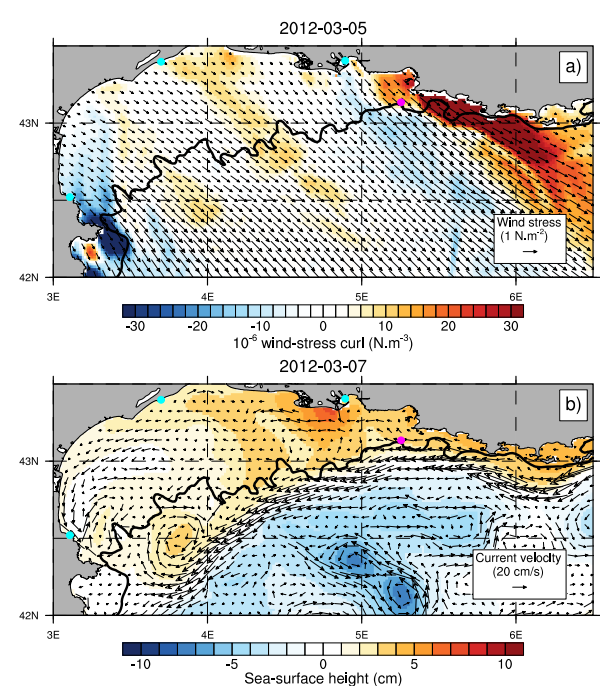

Fig. 10 Top panel: simulated wind-stress (arrows) and wind-stress curl (color shadings) on 2012-03-05. Bottom panel: simulated sea-surface height (color shadings) and $20 \mathrm{~m}$ current velocity (arrows) on 2012-03-07. The locations of the Sonel tide-gauge stations and of the Julio mooring are shown in cyan and magenta, respectively. The $200-\mathrm{m}$ isobath is shown with a bold black line.

1 conditions, the wind-driven cross-shelf circulation is weaker because the Ek-

2 man depth is greater than the water depth.

$3 \quad 4.3$ Combination of both wind patterns

4 Intrusions I1, I4 and I7 are due to a combination of northwesterlies and east-

5 erlies. For I1, the intrusion is triggered by a strong northwesterly wind event 6 on 2012-05-16. Following the mechanisms described in section 4.2, the current 7 starts intruding on the shelf on 2012-05-18. This intrusion is then reinforced 8 by strong easterlies that blow on 2012-05-19 and 2012-05-20, which induce a 9 strong increase in sea-surface height on the western part of the Gulf of Lion 
1 and accelerate the intrusive current as discussed in section 4.1. Similar pat-

2 terns occur for the other two intrusions. In short, intrusion I4 is triggered by northwesterlies blowing on 2012-10-15 and is reinforced by easterlies blowing

4 between 2012-10-18 and 2012-10-20. Intrusion I7 is triggered by the northwest-

5 erlies of 2013-11-14 and reinforced by the easterlies blowing on 2013-11-17 and

$6 \quad 2013-11-18$.

\section{$7 \quad 5$ Discussion and conclusions}

8 In this paper, the physical mechanisms associated with the intrusions of the

9 Northern Current on the eastern side of the Gulf of Lion have been investigated 10 using a combination of in-situ observations (Julio ADCP mooring and Sonel 11 tide-gauge data) and high resolution numerical modelling. We have shown that 12 easterlies and nortwesterlies are likely to favour such intrusions, but through 13 physical mechanisms that are very different in nature. Easterlies generate in14 trusions through a wind-setup mechanism and an increase in sea-surface height 15 along the coast, which induces a geostrophic alongshore northwestward coastal current. Because of the barotropic nature of this mechanism, easterlies are

17 favourable to intrusions independently of the stratification and thus any time

${ }_{18}$ of the year. On the other hand, intrusions in response to northwesterlies princi19 pally occur during stratified conditions and are associated with the relaxation 20 of the upwelling that occurs between Marseille and Toulon (Fig. 1). When the ${ }_{21}$ upwelling develops, the Coriolis force associated with the onshore flow balances ${ }_{22}$ a northwestward pressure gradient force. But when the winds drop and the 
1 upwelling relaxes, the Coriolis force weakens and the pressure force dominates

2 the momentum balance. Consequently, the current is advected northwestward 3 and reaches the Julio location approximately one day after the wind relaxation.

4 This is very close to the mechanism that takes place in the upwelling system

5 off northern California, as discussed for instance in Gan and Allen (2002).

The difference in the physical mechanisms associated with these two wind 7 patterns may be evidenced using the Julio mooring observations and the Al8 adin wind fields by using lead-lag covariance analysis. 3-hourly wind-anomalies 9 are first computed by removing the 2012-2013 mean. The lead-lag covariances between these wind-anomalies and the 3-hourly Julio index (obtained by averaging the half-hourly across-section velocity and by standardising the result12 ing time-series) are then computed for each grid point. These covariance maps 13 measure how much the Julio index and the wind anomalies vary together as 14 a function of the time lag between the two series. They have the same units 15 as the wind-anomalies and the visual inspection of the covariance maps shows that the strength of the covariance increases from 0-lag to 9 hours lag (wind 17 anomalies lead), at which point it shows a pattern similar to an easterly wind 18 pattern (Fig. 11, top panel). The covariance then decreases in the Gulf of Lion until lag 39 hours, where it reaches a minimum. Then, the covariance increases 20 until lag 81 hours (approximately 3 days), when it reaches a secondary maxi${ }_{21}$ mum of weaker amplitude than the first one, looking like a northwesterly-like 22 wind pattern (Fig. 11, bottom panel). This covariance analysis is consistent 
1 with the results described in the above, namely a fast response of the Northern

2 Current intrusions to easterlies and a delayed response to northwesterlies.

A remaining question, however, is whether easterlies or northwesterlies are necessary or sufficient conditions for intrusions of the Northern Current on the eastern part of the Gulf of Lion. Fig. 12a shows the simulated wind-stress at the Julio location and the orientation of strong wind events (defined as periods when the wind-stress amplitude exceeds its mean by one standarddeviation), while Fig.12b shows the simulated volume index over the entire 2012-2013 period. One can notice that, as discussed in section 4.1, strong easterly wind events are always associated with a sharp increase in volume transport across the Julio section, and can therefore be considered as sufficient conditions for intrusions. However, as discussed in section 4.2, northwesterlies are associated with intrusions mainly in summer, when the ocean is stratified (cf. Fig 7). Hence northwesterlies are not sufficient conditions for intrusions. But some intrusion events may also occur when the wind forcing is weak, as for instance in November 2012. These events correspond to meanders of the Northern Current encroaching on the shelf, which are presumably due to instabilities of the Northern Current, as discussed in Gatti (2008). Therefore, neither type of wind is a necessary condition, since intrusions can occur without strong winds.

Nevertheless, the results of the present study are promising since they potentially allow to anticipate cross-shore transports and potential intrusions on the shelf of current-carried plankton or pollution. For instance, Berline et al 


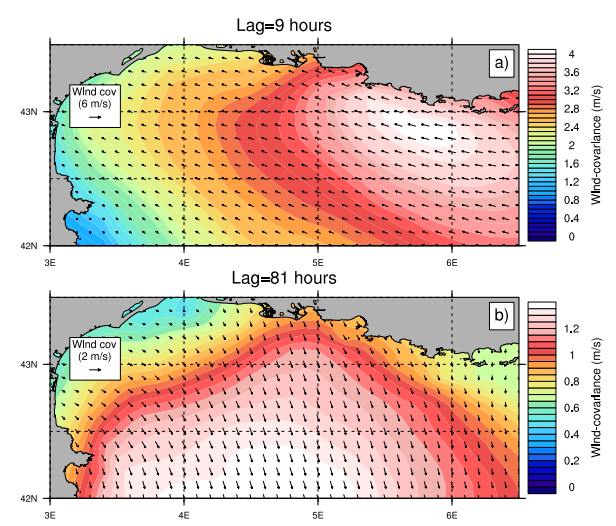

Fig. 11 Covariance at lag 9 hours (top panel) and 81 hours (bottom panel) between the 3-hourly standardised Julio index and the Aladin wind anomalies (wind anomalies lead). Note that the color and arrow scales are different between the two panels.
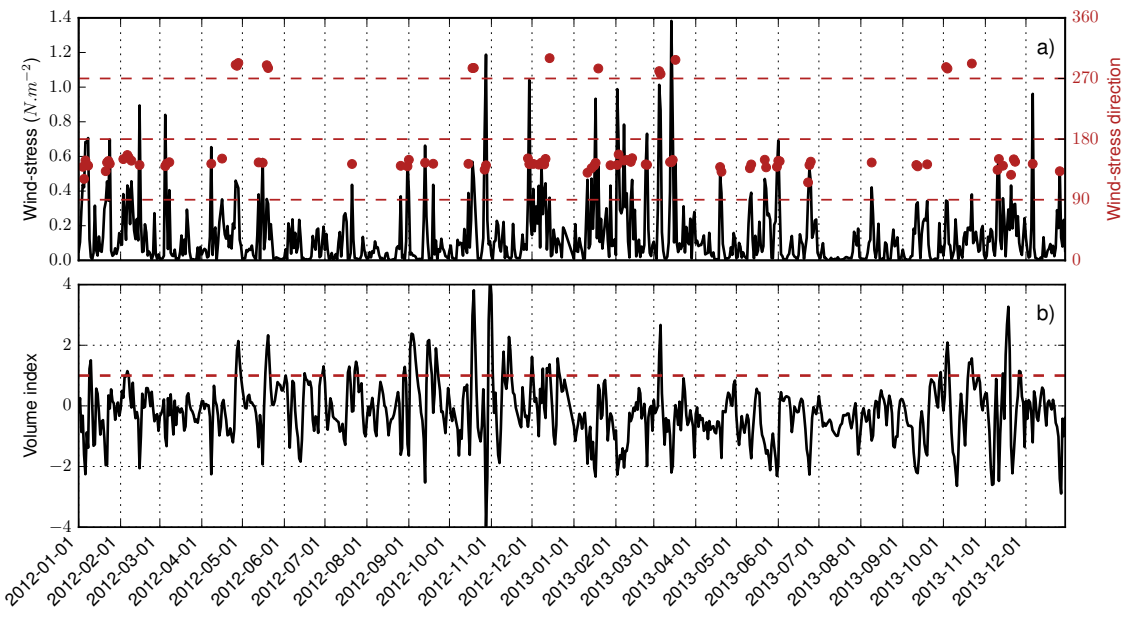

Fig. 12 Top panel: Wind-stress amplitude at the Julio location as simulated by the Glazur64 model. Red dots indicate the direction of strong wind events (defined as periods when the wind-stress amplitude exceeds the mean by one standard-deviation). Southerlies $=0$, Westerlies $=90$, Northerlies $=180$, Easterlies $=270$. Bottom panel: simulated volume index over the entire 2012-2013 period. The dashed line depicts the intrusion detection criteria. 
1 (2013) suggest, using the Glazur64 model configuration and a Lagrangian par-

2 ticle tracking software, that jellyfishes are more abundant on the Ligurian

3 Sea coast when the Northern Current is close to the shore. Given the results

4 described in the present study, one can suggest that increased transport of jel-

5 lyfish on the Gulf of Lion coast may be anticipated in the case of northwesterly

6 winds under stratified conditions, since the intrusions occur one day after the

7 wind relaxes. However, for the intrusions associated with easterlies, since they

8 occur in phase with the wind forcing, the anticipation of jellyfish stranding

9 is likely to depend on the skill of the weather forecast to predict such wind

10 events. Improving our understanding of the physical processes controlling the

11 environmental conditions of coastal regions have significant socio-economical

12 implications, especially regarding fisheries and marine pollution.

Acknowledgements The authors thank Gilles Rougier and Denis Malengros for their technical assistance with the Julio mooring. The Glazur64 simulations were performed using GENCI-IDRIS resources (Grant 2014011707). The analysis and plots of this paper were performed with both Python and the NCAR Command Language (version 6.2.1, 2011, Boulder, Colorado, UCAR/NCAR/CISL/VETS, http://dx.doi.org/10.5065/D6WD3XH5). The authors also acknowledge Julie Gatti, whose thesis strongly influenced this work.

20 André G, Garreau P, Garnier V, Fraunié P (2005) Modelled variability of the sea surface circulation in the North-western Mediterranean Sea and in the Gulf of Lions. Ocean Dynamics 55(3-4):294-308, DOI 10.1007/ 
$1 \quad$ s10236-005-0013-6

2 Astraldi M, Gasparini G, Manzella G, Hopkins T (1990) Temporal Variability

3 of Currents in the Eastern Ligurian Sea. Journal of Geophysical Research-

$4 \quad$ Oceans $95(\mathrm{C} 2): 1515-1522$, DOI 10.1029/JC095iC02p01515

5 Berline L, Zakardjian B, Molcard A, Ourmières Y, Guihou K (2013) Modeling

$6 \quad$ jellyfish Pelagia noctiluca transport and stranding in the Ligurian Sea. Ma-

$7 \quad$ rine Pollution Bulletin 70(12):90-99, DOI 10.1016/j.marpolbul.2013.02.016

8 Bretherton C, Widmann M, Dymnikov V, Wallace J, Blade I (1999) The ef-

9 fective number of spatial degrees of freedom of a time-varying field. Jour-

10 nal of Climate 12(7):1990-2009, DOI 10.1175/1520-0442(1999)012<1990:

$11 \quad$ TENOSD $\rangle 2.0 . \mathrm{CO} ; 2$

12 Cailleau S, Fedorenko V, Barnier B, Blayo E, Debreu L (2008) Comparison of

13 different numerical methods used to handle the open boundary of a regional

14 ocean circulation model of the Bay of Biscay. Ocean Modelling 25(12):1-16,

$15 \quad$ DOI 10.1016/j.ocemod.2008.05.009

16 Caruso MJ, Gawarkiewicz GG, Beardsley RC (2006) Interannual variability

17 of the Kuroshio intrusion in the South China Sea. Journal of Oceanography

$18 \quad 62(4): 559-575$, DOI $10.1007 / \mathrm{s} 10872-006-0076-0$

19 Chen HT, Yan XH, Shaw PT, Zheng Q (1996) A numerical simulation of wind stress and topographic effects on the Kuroshio current path near Taiwan. Journal of physical oceanography 26(9):1769-1802, DOI 10.1175/ 
1 Cruzado A, Velasquez Z (1990) Nutrients and phytoplankton in the Gulf of Lions, northwestern Mediterranean. Continental Shelf Research 10(911):931942, DOI 10.1016/0278-4343(90)90068-W

4 Csanady GT (1982) Circulation in the coastal ocean. Springer

5 Dee DP, Uppala SM, Simmons AJ, Berrisford P, Poli P, Kobayashi S, Andrae U, Balmaseda MA, Balsamo G, Bauer P, Bechtold P, Beljaars ACM, van de Berg L, Bidlot J, Bormann N, Delsol C, Dragani R, Fuentes M, Geer AJ, Haimberger L, Healy SB, Hersbach H, Hlm EV, Isaksen L, Kllberg P, Khler M, Matricardi M, McNally AP, Monge-Sanz BM, Morcrette JJ, Park BK, Peubey C, de Rosnay P, Tavolato C, Thépaut JN, Vitart F (2011) The ERA-Interim reanalysis: configuration and performance of the data assimilation system. Quarterly Journal of the Royal Meteorological Society 137(656):553-597, DOI 10.1002/qj.828

Deshayes J, Curry R, Msadek R (2014) CMIP5 Model Intercomparison of 15 Freshwater Budget and Circulation in the North Atlantic. Journal of Climate 27(9):3298-3317, DOI 10.1175/JCLI-D-12-00700.1

17 Echevin V, Crepon M, Mortier L (2003) Interaction of a coastal current with 18 a gulf: Application to the shelf circulation of the Gulf of Lions in the 19 Mediterranean Sea. Journal of Physical Oceanography 33(1):188-206, DOI ${ }_{20} \quad\{10.1175 / 1520-0485(2003) 033\langle 0188: \mathrm{IOACCW}\rangle 2.0 . \mathrm{CO} ; 2\}$

${ }_{21}$ Estournel C, Broche P, Marsaleix P, Devenon JL, Auclair F, Vehil R (2001) ${ }_{22}$ The Rhone River Plume in Unsteady Conditions: Numerical and Exper${ }_{23}$ imental Results. Estuarine, Coastal and Shelf Science 53(1):25-38, DOI 
2 Fischer C, Montmerle T, Berre L, Auger L, Stefanescu SE (2005) An overview 3 of the variational assimilation in the ALADIN/France numerical weather-

$4 \quad$ prediction system. Quarterly Journal of the Royal Meteorological Society

$5 \quad$ 131(613):3477-3492, DOI 10.1256/qj.05.115

6 Fraysse M, Pairaud I, Ross ON, Faure VM, Pinazo C (2014) Intrusion of 7 Rhone River diluted water into the Bay of Marseille: Generation processes and impacts on ecosystem functioning. Journal of Geophysical ResearchOceans 119(10):6535-6556, DOI 10.1002/2014JC010022

10 Gan J, Allen JS (2002) A modeling study of shelf circulation off northern Cal-

11 ifornia in the region of the Coastal Ocean Dynamics Experiment: Response to relaxation of upwelling winds. Journal of Geophysical Research-Oceans 107(C9):6-1-6-31, DOI 10.1029/2000JC000768

${ }_{14}$ Gatti J (2008) Intrusions du Courant Nord Méditerranéen sur la partie est du 15 plateau continental du Golfe du Lion. PhD thesis, Université Aix-Marseille ${ }_{16}$ Gatti J, Petrenko A, Leredde Y, Devenon J (2006) Modelling the intrusions of the northern current on the eastern part of the gulf of lions continental shelf. In: Geophysical Research Abstracts, vol 8, p 00684 Gawarkiewicz G, Church TM, Luther GW, Ferdelman TG, Caruso M (1992) Large-scale penetration of Gulf Stream water onto the Continental Shelf north of Cape Hatteras. Geophysical Research Letters 19(4):373-376, DOI 10.1029/92GL00225 
1 Guihou K, Marmain J, Ourmières Y, Molcard A, Zakardjian B, Forget P (2013)

2 A case study of the mesoscale dynamics in the North-Western Mediterranean

$3 \quad$ Sea: a combined datamodel approach. Ocean Dynamics 63(7):793-808, DOI

$4 \quad 10.1007 / \mathrm{s} 10236-013-0619-\mathrm{z}$

5 Huthnance JM (1995) Circulation, exchange and water masses at the ocean

6 margin: the role of physical processes at the shelf edge. Progress in Oceanog-

$7 \quad$ raphy $35(4): 353-431$, DOI $10.1016 / 0079-6611(95) 80003-\mathrm{C}$

8 Korotaev G, Oguz T, Nikiforov A, Koblinsky C (2003) Seasonal, interannual, 9 and mesoscale variability of the Black Sea upper layer circulation derived

10 from altimeter data. Journal of Geophysical Research-Oceans 108(C4), DOI

$11 \quad 10.1029 / 2002 J C 001508$

12 Largier JL (2003) Considerations in Estimating Larval Dispersal Distances

13 from Oceanographic Data. Ecological Applications 13(1):71-89, DOI 10.

$14 \quad$ 1890/1051-0761(2003)013[0071:CIELDD]2.0.CO;2

15 Lentz SJ (2001) The Influence of Stratification on the Wind-Driven Cross-Shelf

${ }_{16}$ Circulation over the North Carolina Shelf. Journal of Physical Oceanography 31(9):2749-2760, DOI 10.1175/1520-0485(2001)031〈2749:TIOSOT $\rangle 2.0 . C O$; 2 Quiones R (2000) Exploring continental margin carbon fluxes on a global scale. Eos, Transactions American Geophysical Union 81(52):641-644, DOI 
1 Madec G (2008) NEMO ocean engine. Tech. rep., Institut Pierre-Simon

2 Laplace

3 Mantoura RFC, Martin JM, Wollast R, et al (1991) Ocean margin processes

$4 \quad$ in global change. John Wiley and Sons Ltd.

5 Millot C (1979) Wind induced upwellings in the Gulf of Lions. Oceanologica

$6 \quad$ Acta 2(3):261-274

7 Millot C (1990) The Gulf of Lions' hydrodynamics. Continental Shelf Research

$8 \quad 10(911): 885-894$, DOI 10.1016/0278-4343(90)90065-T

9 Millot C (1999) Circulation in the Western Mediterranean Sea. Journal of

$10 \quad$ Marine Systems 20(1-4):423-442, DOI 10.1016/S0924-7963(98)00078-5

${ }_{11}$ Millot C, Wald L (1980) The effect of Mistral wind on the Ligurian current

12 near Provence. Oceanologica Acta 3(4):399-402

${ }_{13}$ Oey LY, Atkinson LP, Blanton JO (1987) Shoreward intrusion of upper

${ }_{14}$ Gulf Stream water onto the US southeastern continental shelf. Journal of physical oceanography 17(12):2318-2333, DOI 10.1175/1520-0485(1987)

$16 \quad 017\langle 2318:$ SIOUGS $\rangle 2.0 . \mathrm{CO} ; 2$

${ }_{17}$ Oguz T, Besiktepe S (1999) Observations on the Rim Current structure,

${ }_{18}$ CIW formation and transport in the western Black Sea. Deep Sea Re-

19 search Part I: Oceanographic Research Papers 46(10):1733-1753, DOI 10.1016/S0967-0637(99)00028-X

${ }_{21}$ Ourmières Y, Zakardjian B, Beranger K, Langlais C (2011) Assessment of a

22 NEMO-based downscaling experiment for the North-Western Mediterranean 

and altimetry products. Ocean Modelling 39(3-4):386-404, DOI 10.1016/j. ocemod.2011.06.002

3 Petrenko A (2003) Variability of circulation features in the gulf of lion NW

$4 \quad$ Mediterranean Sea. Importance of inertial currents. Oceanologica Acta

$5 \quad 26(4): 323-338$, DOI 10.1016/S0399-1784(03)00038-0

6 Ponte RM (2006) Low-frequency sea level variability and the inverted barom-

7 eter effect. Journal of Atmospheric and Oceanic Technology 23(4):619-629,

$8 \quad$ DOI $10.1175 /$ JTECH1864.1

9 Reffray G, Fraunié P, Marsaleix P (2004) Secondary flows induced by wind 10 forcing in the Rhône region of freshwater influence. Ocean Dynamics $11 \quad 54(2): 179-196$, DOI 10.1007/s10236-003-0079-y

12 Ross O, Fraysse M, Pinazo C, Pairaud I () Impact of an intrusion by the ${ }_{13}$ Northern Current on the biogeochemistry in the eastern Gulf of Lion, NW $14 \quad$ Mediterranean. Estuarine, Coastal and Shelf Science

15 Schaeffer A, Garreau P, Molcard A, Fraunie P, Seity Y (2011) Influence of 16 high-resolution wind forcing on hydrodynamic modeling of the Gulf of Lions. Ocean Dynamics 61(11):1823-1844, DOI 10.1007/s10236-011-0442-3

${ }_{18}$ Tang T, Hsueh Y, Yang Y, Ma J (1999) Continental slope flow northeast of Taiwan. Journal of Physical Oceanography 29(6):1353-1362, DOI 10.1175/ 1520-0485(1999)029〈1353:CSFNOT $\rangle 2.0 . C O ; 2$

${ }_{21}$ Ulses C, Estournel C, Puig P, Durrieu de Madron X, Marsaleix P (2008) ${ }_{22}$ Dense shelf water cascading in the northwestern mediterranean during the ${ }_{23}$ cold winter 2005: Quantification of the export through the gulf of lion and 
1 the catalan margin. Geophysical Research Letters 35(7):1-6, DOI 10.1029/

2 2008GL033257, URL http://dx.doi.org/10.1029/2008GL033257, 107610

3 Wolanski E, Norro A, King B (1995) Water circulation in the Gulf of Papua.

$4 \quad$ Continental Shelf Research 15(2):185-212, DOI 10.1016/0278-4343(94)

$5 \quad$ E0026-I

6 Wu CR, Tang T, Lin S (2005) Intra-seasonal variation in the velocity field of $7 \quad$ the northeastern South China Sea. Continental Shelf Research 25(17):2075-

$8 \quad 2083$, DOI $10.1016 /$ j.csr.2005.03.005 